\title{
Chapter 8 \\ Doubled Haploidy as a Tool for Chimaera Dissolution of TALEN-Induced Mutations in Barley
}

\author{
Maia Gurushidze, Hannes Trautwein, Petra Hoffmeister, Ingrid Otto, \\ Andrea Müller, and Jochen Kumlehn
}

\begin{abstract}
Site-specific genome engineering is a breakthrough technology that facilitates the functional validation of genes and offers versatile novel opportunities of crop improvement. In the approach described in this chapter, the two units of transcription activator-like effector nucleases (TALENs) required for site-directed cleavage activity are separately used to produce homozygous transgenic lines, each carrying only one unit of the TALEN pair. Crossings of these plants result in pairwise combination of both TALEN units, which causes their activation during early zygotic embryogenesis in the hybrid caryopses and facilitates site-directed mutagenesis with unprecedented efficiency in a Triticeae species. As revealed by sequencing of target-specific PCR amplicons, the individual primary mutants are not only heterozygous for the target gene but also chimaeric typically harbouring multiple mutant alleles. We demonstrate the highly efficient production of homozygous mutant lines from the chimaeric primary mutants using haploid microspores as embryogenic founder cells for the generation of doubled haploid plants.
\end{abstract}

Keywords Customizable endonucleases • Genome engineering • Haploid technology • Pollen embryogenesis $\bullet$ Site-directed mutagenesis

M. Gurushidze • H. Trautwein • P. Hoffmeister • I. Otto • A. Müller • J. Kumlehn ( $\square)$ Plant Reproductive Biology, Leibniz Institute of Plant Genetics and Crop Plant Research (IPK), Corrensstrasse 3, 06466 Seeland/OT, Gatersleben, Germany

e-mail: kumlehn@ipk-gatersleben.de 


\subsection{Introduction}

\subsubsection{Generation of Primary Mutants by Cross-Combination of Parental Lines Carrying Complementary Single TALEN Units}

Transcription activator-like effector nucleases (TALENs) represent a universal tool for site-directed mutagenesis as they are capable of inducing double-strand breaks (DSBs) at user-defined positions in the genome. The processing of a resulting DSB by the host cell's DNA repair machinery can lead to nucleotide deletions or insertions (indels) at the breakage site. TALENs are fusion proteins between a customizable, target-specific DNA binding domain (Moscou and Bogdanove 2009) and the nucleolytic domain of FokI endonuclease, with the former directing the nuclease to the genomic site of choice, while the latter cleaves the double-strand DNA (Christian et al. 2010). However, FokI exerts its activity only in a dimeric format, which is achieved by introducing a pair of TALEN units binding in appropriate distance and orientation to the two strands of the DNA (Bitinaite et al. 1998). Conventionally, the expression cassettes of left and right TALEN units are cloned into a single T-DNA used for plant transformation. As an alternative, two separate T-DNAs can be used in co-transformation approaches.

In barley, immature embryos or embryogenic pollen cultures have been used as recipient material for Agrobacterium-mediated transfer of TALEN-coding expression units, and both methods have resulted in moderate efficiency of site-specific mutagenesis (Wendt et al. 2013; Gurushidze et al. 2014). However, somatic mutations occurring in the primary transformants are not necessarily inherited to the next generation (Wendt et al. 2014). The advantage of the approach described in this chapter is that it induces mutations in cells whose genetic make-up is particularly likely to be transmitted to the generative tissues including the female and male gametophytes (i.e. embryo sac and pollen, respectively) of a given plant. To this end, the two TALEN units required for site-directed cleavage activity at the model gfp gene were separately used to produce homozygous transgenics, each carrying and expressing only one of these units. Pairs of resultant transgenics that express complementary TALEN units at homozygous state were used for reciprocal crosses. An additional advantage of the approach is that it allows validating the expression of the individual TALEN units in the plants before crossing. The combination of both complementary TALEN units within a hybrid plant results in TALEN activation during early zygotic embryogenesis, which is associated with extremely high efficiency of targeted mutagenesis in cells that genetically contribute to the germ line towards the next generation. As shown by sequencing of the cloned target-specific PCR amplicons, multiple mutant $g f p$ alleles were present in each of the analysed seedlings, indicating unprecedented efficiency in site-directed mutagenesis in a Triticeae species. Thus, in the presented approach, there are only two successful transformation events necessary to generate the two lines carrying complementary single TALEN units. Once they are established in homozygous 
state, no further transformation is necessary to generate mutants. A huge number of independent mutants can be generated by crossing these pre-validated single TALEN unit lines, which is a particularly valuable option, especially in plants that are not readily transformable.

\subsubsection{Chimaerism Upon TALEN-Induced Targeted Mutagenesis}

As mentioned above, every analysed individual of the hybrid offspring contained multiple mutant $g f p$ sequences, i.e. produced TALEN mutants are chimaeric regarding the induced mutations. Virtually, the TALEN pair expressed in each cell could initiate independent mutation events resulting in extremely high diversity of the induced sequence modifications within one individual. Indeed, by sequencing up to 65 individual clones of the PCR amplicons derived from the target gene ( $g f p)$, as many as 61 different mutations were detected per hybrid seedling. Although chimaerism is a quite often occurring phenomenon in targeted mutagenesis, the proportion of heritable mutations strongly depends on the method. While none of the TALEN-induced mutations proved heritable among the seedlings of primary barley-mutant plants produced via immature embryo transformation (Wendt et al. 2014), multiple mutations were inherited within doubled haploid siblings using the method presented in this chapter (see Note 1).

\subsubsection{Haploid Technology}

Haploid technology is one of the most powerful biotechnological tools in plant breeding and functional genomic studies. The advantage of haploid plants is that homozygosity can be readily achieved at all loci via whole-genome duplication in just one generational step. Nowadays, haploid technology is also exploited to produce instantly homozygous mutants and transgenics (Kumlehn et al. 2006; Gurushidze et al. 2014).

Pollen embryogenesis is a phenomenon that allows generating haploid and doubled haploid plants from immature pollen. In this approach, each doubled haploid individual originates from a unique gametophytic cell, and accordingly, the resulting population of doubled haploid plants represents a collection of meiotically independently recombined but genetically fixed individuals. In this chapter, we describe the utilization of pollen embryogenesis for chimaera dissolution of TALEN-induced mutations in barley. 


\subsection{Materials}

\subsubsection{Growth of Parental Lines and Primary Mutant Plants}

1. The parental lines used in crossing experiments carrying stably incorporated either left or right TALEN units represent winter-type cultivar 'Igri'. Parental lines were produced as described in the Chap. 7.

2. Grains of the parental lines were germinated on Substrate 2 (Klasmann, Germany), which is a 3:1:2 mixture of garden mulch, sand and white and black peats, respectively.

3. The soil substrate used after vernalization is a mixture of compost, Klasmann Substrate 2 and sand mixed at a ratio of 2:2:1. Osmocote $(19 \% \mathrm{~N}, 6 \% \mathrm{P}$ and $12 \% \mathrm{~K}$ ) was used as a fertilizer.

4. Petuniensubstrat (Klasmann, Germany) was used for the acclimation of in vitro regenerants to grow on soil substrate.

\subsubsection{Stock Solutions and Culture Media}

\subsubsection{Solutions for Isolation, Purification and Induction of Embryogenic Development of Immature Pollen}

\section{Carbohydrates}

Mannitol $(0.4 \mathrm{M}, 72.9 \mathrm{~g} / \mathrm{L})$ : autoclaved and stored at $4{ }^{\circ} \mathrm{C}$.

Maltose $\cdot \mathrm{H}_{2} \mathrm{O}(1 \mathrm{M}$, Sigma grade I, $360.3 \mathrm{~g} / \mathrm{L})$ : filter sterilized and stored at room temperature.

Maltose $\cdot \mathrm{H}_{2} \mathrm{O}(1 \mathrm{M}$, standard quality, $360.3 \mathrm{~g} / \mathrm{L})$ : filter sterilized and stored at room temperature.

Maltose $\cdot \mathrm{H}_{2} \mathrm{O}(0.55 \mathrm{M}$, standard quality, $198.2 \mathrm{~g} / \mathrm{L})$ : filter sterilized and stored at $4{ }^{\circ} \mathrm{C}$.

\section{Mineral salts}

NaFeEDTA ( $75 \mathrm{mM}, 27.5 \mathrm{~g} / \mathrm{L})$ : filter sterilized and stored at $4{ }^{\circ} \mathrm{C}$

$\mathrm{CaCl}_{2}\left(1 \mathrm{M}, 147 \mathrm{~g} / \mathrm{L} \mathrm{CaCl} 2 \cdot 2 \mathrm{H}_{2} \mathrm{O}\right)$ : filter sterilized and stored at $4{ }^{\circ} \mathrm{C}$

$\mathrm{CuSO}_{4} \cdot 5 \mathrm{H}_{2} \mathrm{O}(10 \mathrm{mM}, 2.5 \mathrm{~g} / \mathrm{L})$ : filter sterilized and stored at $4{ }^{\circ} \mathrm{C}$

$\mathrm{NH}_{4} \mathrm{Cl}(1 \mathrm{M}, 53.5 \mathrm{~g} / \mathrm{L})$ : filter sterilized and stored at $4{ }^{\circ} \mathrm{C}$

$\mathrm{K}$ macro minerals $(20 \times): 1.6 \mathrm{~g} / \mathrm{L} \mathrm{NH}_{4} \mathrm{NO}_{3}, 40.4 \mathrm{~g} / \mathrm{L} \mathrm{KNO}_{3}, 6.8 \mathrm{~g} / \mathrm{L} \mathrm{KH}_{2} \mathrm{PO}_{4}, 8.8 \mathrm{~g} /$

$\mathrm{L} \mathrm{CaCl}_{2} \cdot 2 \mathrm{H}_{2} \mathrm{O}$ and $4.9 \mathrm{~g} / \mathrm{L} \mathrm{MgSO}_{4} \cdot 7 \mathrm{H}_{2} \mathrm{O}$; filter sterilized and stored at $4{ }^{\circ} \mathrm{C}$

$\mathrm{K} 4 \mathrm{~N}$ macro minerals $(20 \times)$ : $6.4 \mathrm{~g} / \mathrm{L} \mathrm{NH}_{4} \mathrm{NO}_{3}, 72.8 \mathrm{~g} / \mathrm{L} \mathrm{KNO}_{3}, 6.8 \mathrm{~g} / \mathrm{L} \mathrm{KH}_{2} \mathrm{PO}_{4}$, $8.8 \mathrm{~g} / \mathrm{L} \mathrm{CaCl}{ }_{2} \cdot 2 \mathrm{H}_{2} \mathrm{O}$ and $4.9 \mathrm{~g} / \mathrm{L} \mathrm{MgSO}_{4} \cdot 7 \mathrm{H}_{2} \mathrm{O}$; filter sterilized and stored at $4{ }^{\circ} \mathrm{C}$

$\mathrm{K}$ micro minerals $(1000 \times): 8.4 \mathrm{~g} / \mathrm{L} \quad \mathrm{MnSO}_{4} \cdot \mathrm{H}_{2} \mathrm{O}, 3.1 \mathrm{~g} / \mathrm{L} \quad \mathrm{H}_{3} \mathrm{BO}_{3}, 7.2 \mathrm{~g} / \mathrm{L}$ $\mathrm{ZnSO}_{4} \cdot 7 \mathrm{H}_{2} \mathrm{O}, 120 \mathrm{mg} / \mathrm{L} \mathrm{Na} \mathrm{MoO}_{4} \cdot 2 \mathrm{H}_{2} \mathrm{O}, 25 \mathrm{mg} / \mathrm{L} \mathrm{CuSO}_{4} \cdot 5 \mathrm{H}_{2} \mathrm{O}, 24 \mathrm{mg} / \mathrm{L}$ $\mathrm{CoCl}_{2} \cdot 6 \mathrm{H}_{2} \mathrm{O}$ and $170 \mathrm{mg} / \mathrm{L} \mathrm{KI}$; filter sterilized and stored at $4{ }^{\circ} \mathrm{C}$ 


\section{Organic supplements}

KM organics $(100 \times$, Sigma K-3129): $2 \mathrm{mg} / \mathrm{L} p$-aminobenzoic acid, $200 \mathrm{mg} / \mathrm{L} \mathrm{L}-$ ascorbic acid, $1 \mathrm{mg} / \mathrm{L}$ D-biotin, $100 \mathrm{mg} / \mathrm{L}$ D-calcium pantothenate, $2 \mathrm{mg} / \mathrm{L}$ cyanocobalamin, $40 \mathrm{mg} / \mathrm{L}$ folic acid, $10 \mathrm{~g} / \mathrm{L}$ myo-inositol, $100 \mathrm{mg} / \mathrm{L}$ nicotinamide, $100 \mathrm{mg} / \mathrm{L}$ pyridoxine $\cdot \mathrm{HCl}, 1 \mathrm{mg} / \mathrm{L}$ retinol, $20 \mathrm{mg} / \mathrm{L}$ riboflavin and $100 \mathrm{mg} / \mathrm{L}$ thiamine $\cdot \mathrm{HCl}$; stored at $-20^{\circ} \mathrm{C}$.

Gamborg B5 organics $(1000 \times): 100 \mathrm{mg} / \mathrm{L}$ myo-inositol, $1 \mathrm{mg} / \mathrm{L}$ nicotinic acid, $1 \mathrm{mg} / \mathrm{L}$ pyridoxine $\cdot \mathrm{HCl}$ and $10 \mathrm{mg} / \mathrm{L}$ thiamine $\cdot \mathrm{HCl}$; filter sterilized and stored at $-20{ }^{\circ} \mathrm{C}$.

L-Glutamine $(37 \mathrm{mg} / \mathrm{ml})$ : dissolved by adding a few drops of $0.1 \mathrm{M} \mathrm{KOH}$ and heating in a water bath, filter sterilized and stored at $-20{ }^{\circ} \mathrm{C}$.

6-Benzylaminopurine (BAP, $1 \mathrm{mM}$ ): $225 \mathrm{mg} / \mathrm{L}$ dissolved in $30 \mathrm{ml}$ hot $\mathrm{H}_{2} \mathrm{O}$ and 3-5 drops $1 \mathrm{M} \mathrm{NaOH}$, made up to the final volume, filter sterilized and stored at $4{ }^{\circ} \mathrm{C}$.

Morpholinoethanesulfonic acid monohydrate (MES, $1 \mathrm{M}, 213.2 \mathrm{~g} / \mathrm{L}, \mathrm{pH}=5.0$, $\mathrm{pH}=5.5$ and $\mathrm{pH}=5.9$ ): dissolved in $40 \mathrm{ml} \mathrm{H}_{2} \mathrm{O}$, the $\mathrm{pH}$ adjusted with $\mathrm{KOH}$ (few pellets), stored at room temperature overnight, and the $\mathrm{pH}$ readjusted with either $\mathrm{KOH}$ or $\mathrm{HCl}$, made up to the final volume, filter-sterilized and stored at $4{ }^{\circ} \mathrm{C}$.

Gelling agent

Phytagel $(2 \times, 6 \mathrm{~g} / \mathrm{L})$ : suspended in cold water of double-distilled quality (at best $1.5 \mathrm{~g}$ Phytagel per $250 \mathrm{ml}$ unit), autoclaved and stored at room temperature.

\subsubsection{Nutrient Media for Embryogenic Pollen Culture and Plant Regeneration}

1. Starvation medium barley (SMB): $1 \mathrm{ml} / \mathrm{L} \mathrm{CaCl}_{2}, 1 \mathrm{ml} / \mathrm{L} \mathrm{NH}_{4} \mathrm{Cl}, 2 \mathrm{ml} / \mathrm{L} \mathrm{MES}$ $\mathrm{pH} 5.5$ and $400 \mathrm{ml} / \mathrm{L}$ mannitol stocks; filter-sterilized and stored at $4{ }^{\circ} \mathrm{C}$.

2. Barley pollen culture (KBP) medium: $50 \mathrm{ml} / \mathrm{L} \mathrm{K}$ macro, $1 \mathrm{ml} / \mathrm{L} \mathrm{K}$ micro, $1 \mathrm{ml} / \mathrm{L}$ $\mathrm{NaFeEDTA}, 10 \mathrm{ml} / \mathrm{L} \mathrm{KM}$ organics, $12 \mathrm{ml} / \mathrm{L} \mathrm{L}$-glutamine, $4 \mathrm{ml} / \mathrm{L}$ BAP and $250 \mathrm{ml} / \mathrm{L}$ maltose (1 M, Sigma Grade I) stocks; $\mathrm{pH}$ adjusted to 5.9 and stored at $4{ }^{\circ} \mathrm{C}$.

3. Solid barley pollen culture (KBP4P) medium: for a final volume of $0.5 \mathrm{~L}$ $\mathrm{KBP} 4 \mathrm{P}$, appropriate amounts of $50 \mathrm{ml} / \mathrm{L} \mathrm{K}$ macro minerals, $1 \mathrm{ml} / \mathrm{L} \mathrm{K}$ micro minerals, $1 \mathrm{ml} / \mathrm{L} \mathrm{NaFeEDTA}, 10 \mathrm{ml} / \mathrm{L} \mathrm{KM}$ organics, $250 \mathrm{ml} / \mathrm{L}$ maltose $(1 \mathrm{M}$, standard quality), $1 \mathrm{ml} / \mathrm{L} \mathrm{BAP}$ and $12 \mathrm{ml} / \mathrm{L}$ L-glutamine stocks were mixed to an intermediate volume of $250 \mathrm{ml}$ (doubled concentrated), adjusted to $\mathrm{pH} 5.9$, heated to about $40{ }^{\circ} \mathrm{C}$ and then mixed (1:1) with $250 \mathrm{ml}$ Phytagel stock (melted by heating).

4. Regeneration (K4NB) medium: for a final volume of $0.5 \mathrm{~L} \mathrm{~K} 4 \mathrm{NB}$, appropriate amounts of $50 \mathrm{ml} / \mathrm{L} \mathrm{K} 4 \mathrm{~N}$ macro minerals, $1 \mathrm{ml} / \mathrm{L} \mathrm{K}$ micro minerals, $0.75 \mathrm{ml} / \mathrm{L}$ NaFeEDTA, $1 \mathrm{ml} / \mathrm{L}$ B5 organics, $4 \mathrm{ml} / \mathrm{L}$ L-glutamine, $100 \mathrm{ml} / \mathrm{L}$ maltose $(1 \mathrm{M}$, standard quality), $1 \mathrm{ml} / \mathrm{L} \mathrm{BAP}$ and $0.49 \mathrm{ml} / \mathrm{L} \mathrm{CuSO}_{4}$ stocks were mixed to an 
intermediate volume of $250 \mathrm{ml}$ (double concentrated), adjusted to $\mathrm{pH} 5.9$, heated to about $40{ }^{\circ} \mathrm{C}$ and then mixed (1:1) with $250 \mathrm{ml}$ Phytagel stock (melted by heating).

\subsubsection{Materials for the Isolation of Embryogenic Pollen Culture and Plant Regeneration}

1. Refrigerated centrifuge equipped with swing-out baskets.

2. Waring blender (heat sterilizable).

3. Sterile Petri dishes with lid $(3.5 \mathrm{~cm}$ in diameter $)$.

4. Sterile Petri dishes with lid (10 $\mathrm{cm}$ in diameter).

5. Divided Petri dishes with two sections and lid $(10 \mathrm{~cm}$ in diameter).

6. Sterile screw cap polypropylene centrifuge tubes (round bottom $12 \mathrm{ml}$ and skirted conical $50 \mathrm{ml}$ tubes).

7. Magenta boxes (autoclaved).

8. Nylon mesh (100 $\mu \mathrm{m}$ grid, autoclaved).

9. Haemocytometer (type Rosenthal).

10. Filter paper discs ( $7 \mathrm{~cm}$ diameter, ash-free, autoclaved).

11. Sterile filter-stopped tips $(1 \mathrm{ml})$ for standard pipettes.

\subsubsection{Materials for the Molecular Analyses of Pollen-Derived Plants}

1. Liquid nitrogen.

1. Safe-lock tubes $(1.5$ and $2 \mathrm{ml})$.

2. Phenol (equilibrated, stabilized) to chloroform to isoamylalcohol $(25: 24: 1)$ (AppliChem, Darmstadt, Germany).

3. Isopropyl alcohol $(\geq 99.8 \%)$.

4. Ethanol $(70 \%)$.

5. Taq DNA polymerase with respective PCR buffer.

6. $\mathrm{MgCl}_{2}(25 \mathrm{mM})$.

7. Primers for amplification of target gene $g f p$ (forward: GH-GFP-R2 TACGGCAAGCTGACCCTGAA; GGTCACGAACTCCAGCAGGA).

8. QIAquick PCR purification kit (QIAGEN, Hilden, Germany).

9. Cloning pGEM-T vector kit (Promega, Madison, WI).

10. Agarose gel $(0.8 \%)$; freshly prepared.

11. Gel electrophoresis system (Bio-Rad, Munich, Germany). 


\subsubsection{Materials for Ploidy Determination and Colchicine- Induced Whole-Genome Duplication}

1. Flow cytometer, e.g. Ploidy Analyser I (Partec, Münster, Germany).

2. Nylon mesh filters, e.g. CellTrics (30 $\mu \mathrm{m}$ mesh diameter, Partec).

3. Staining buffer, e.g. CyStain UV Ploidy staining solution (Partec).

4. Wire brush.

5. Sterile screw cap polypropylene centrifuge conical tubes $(50 \mathrm{ml})$.

6. $0.1 \% \mathrm{w} / \mathrm{v}$ colchicine, supplied with three drops of Tween per $100 \mathrm{ml}$.

\subsection{Methods}

\subsubsection{Growth of Primary Mutant Plants}

1. T1 grains of homozygous transgenic plants of cv. 'Igri' expressing single TALEN units were germinated (see Note 2) on germination substrate in a chamber providing $12 \mathrm{~h}$ photoperiod $\left(136 \mu \mathrm{mol} \mathrm{m} \mathrm{m}^{-2} \mathrm{~s}^{-1}\right.$ photon flux density) with temperature regime of $14 / 12{ }^{\circ} \mathrm{C}$ for light/dark phases for 2 weeks.

2. Vernalization of the seedlings was performed at $4{ }^{\circ} \mathrm{C}$ under an $8 \mathrm{~h}$ photoperiod for 8 weeks.

3. The seedlings were then transferred to $18 \mathrm{~cm}$ diameter pots, fertilized by providing $15 \mathrm{~g}$ Osmocote and grown under controlled conditions as described in Step 1 of this section.

\subsubsection{Crossing of Pairs of Complementary Single TALEN Plants and Analysis of Hybrid Plants}

Left and right TALEN unit-carrying homozygous barley lines were grown under the conditions described above (Sect. 8.3.1). Crossing partners were chosen in such a way that the resulting hybrids possess both TALEN units. After reciprocal crossing of the selected TALEN carrying lines, the hybrid plants were analysed as follows: the target sequence ( $g f p)$ was amplified and cloned into pGEM-T vector. The DNA was isolated from various numbers of positive clones and sequenced to gain preliminary information about mutation frequencies. 


\subsubsection{Spike Preparation}

Spikes were harvested when the awns had just emerged from the sheath of the flag leaf, boots were surface-sterilized by spraying with $70 \%$ ethanol, and the flag leaf sheath was removed under aseptic conditions. Dissected spikes were placed in one section of a divided Petri dish (10 cm in diameter), whereas the other section was supplied with sterile water to provide saturated humidity in the dish's airspace. The dishes were sealed and placed at $4{ }^{\circ} \mathrm{C}$ for 2 weeks in the fridge.

\subsubsection{Isolation, Purification and Inductive Treatment of Immature Pollen}

1. Ten to fifteen pretreated spikes were chopped into ca. $1 \mathrm{~cm}$ pieces and macerated in a blender in the presence of $20 \mathrm{ml} 0.4 \mathrm{M}$ mannitol. Two bursts of $15 \mathrm{~s}$ each were performed in a Waring blender set on 'low' speed (see Note 3).

2. The macerate was filtered through a $100 \mu \mathrm{m}$ mesh into a Magenta box. The blender was rinsed with $10 \mathrm{ml}$ of $0.4 \mathrm{M}$ mannitol, which was also passed through the mesh.

3. The debris remaining on the mesh was squeezed gently with tweezers transferred back to the blender and re-macerated twice for $10 \mathrm{~s}$ in another $10 \mathrm{ml}$ of $0.4 \mathrm{M}$ mannitol. The macerate was again filtered through the mesh, and the blender was rinsed again with $10 \mathrm{ml}$ of $0.4 \mathrm{M}$ mannitol. The latter was then also passed through the mesh into a Magenta box.

4. The material collected in the Magenta box was transferred to the $50 \mathrm{ml}$ centrifuge tube, and the Magenta box flushed with $5 \mathrm{ml} 0.4 \mathrm{M}$ mannitol, which was also added to the same tube. The suspension was centrifuged $(100 \times g, 10 \mathrm{~min}$, $\left.4{ }^{\circ} \mathrm{C}\right)$.

5. The supernatant was discarded, and the pellet was re-suspended in $3 \mathrm{ml} 0.55 \mathrm{M}$ maltose in a round-bottomed $12 \mathrm{ml}$ tube. The centrifuge tube was flushed with $2 \mathrm{ml} \mathrm{0.4} \mathrm{M} \mathrm{mannitol,} \mathrm{which} \mathrm{was} \mathrm{poured} \mathrm{carefully} \mathrm{over} \mathrm{the} \mathrm{top} \mathrm{of} \mathrm{the} 0.55 \mathrm{M}$ maltose suspension, so that two distinct liquid layers were formed.

6. The tube containing these two layers was subjected to density gradient centrifugation in swing-out baskets $\left(100 \times g, 10 \mathrm{~min}, 4{ }^{\circ} \mathrm{C}\right)$ (see Note 4). After the centrifugation step, the immature pollen accumulated in the interphase. The interphase was carefully withdrawn by pipetting, transferred to a fresh $50 \mathrm{ml}$ tube to which $10 \mathrm{ml} 0.4 \mathrm{M}$ mannitol was added and resuspended with gentle shaking. $100 \mu \mathrm{L}$ aliquot of the material was placed into a haemocytometer cell to estimate the population density. Meanwhile the remaining microspores were pelleted by centrifugation $\left(100 \times g, 10 \mathrm{~min}, 4^{\circ} \mathrm{C}\right)$. After centrifugation, the tube was left in the centrifuge for ca. 5 min before the supernatant was withdrawn to allow settling down of the floating pollen. 
7. The pollen was resuspended in SMB with a density of 200,000 microspores $/ \mathrm{ml}$; aliquots of $1 \mathrm{ml}$ pollen suspension were transferred into $3.5 \mathrm{~cm}$ Petri dishes. The dishes were sealed and held in the dark at $25{ }^{\circ} \mathrm{C}$ for $48 \mathrm{~h}$ to induce embryogenic competence.

\subsubsection{Regeneration of Pollen-Derived Plants}

1. After the inductive treatment, the SMB was withdrawn through a $1 \mathrm{ml}$ pipette tip (see Note 5). The medium was then replaced with $1 \mathrm{ml} \mathrm{KBP}$ medium, and the sealed plates were further held at $25^{\circ} \mathrm{C}$ in the dark for another 2 weeks.

2. Then, the formed embryogenic calli were transferred to an ash-free filter disc placed over solid KBP4P medium in a $10 \mathrm{~cm}$ Petri dish. After sealing, these dishes were held in the dark at $25^{\circ} \mathrm{C}$ for 2 weeks.

3. Calli that reached more than $1 \mathrm{~mm}$ in diameter can be transferred into a $10 \mathrm{~cm}$ Petri plate containing K4NB medium, while those which have not yet reached this size can be kept for another week on KBP4P before being transferred to regeneration medium. The sealed $\mathrm{K} 4 \mathrm{NB}$ plates were held in the dark at $25^{\circ} \mathrm{C}$ for 1 week and then transferred into the light.

4. After 3 weeks, the calli and any emerging regenerants were transferred to tissue culture boxes containing K4NB and subcultured twice at 3-week intervals.

5. Regenerated plants with roots were transferred to $6 \mathrm{~cm}$ diameter pots filled with soil substrate (Klasmann Petuniensubstrat) and placed in a tray covered by a transparent plastic hood to maintain a high-humidity environment. The tray was held in a chamber providing a $12 \mathrm{~h}$ photoperiod $\left(136 \mu \mathrm{mol} \mathrm{m} \mathrm{m}^{-2} \mathrm{~s}^{-1}\right.$ photon flux density) and a temperature regime of $14 / 12{ }^{\circ} \mathrm{C}$ for light/dark phases, respectively.

6. After 2 weeks, the hood was removed and the tray left uncovered for a further week. The plantlets were then vernalized for 8 weeks at $4{ }^{\circ} \mathrm{C}$ under an $8 \mathrm{~h}$ photoperiod.

7. After vernalization, the plants were grown under the conditions described for the donor plants.

\subsubsection{Analysis of Pollen-Derived Plants}

\subsubsection{Ploidy Determination}

During the vernalization period, flow cytometry of leaf tissue was used to determine the ploidy level as follows:

1. For the isolation of nuclei, a leaf sample was supplied with ice-cold staining buffer (CyStain UV Ploidy staining solution, Partec, Münster, Germany), and the leaf tissue was disintegrated gently with a wire brush. 
2. The resulting suspension was then filtered through a nylon mesh filter (CellTrics, $30 \mu \mathrm{m}$ mesh diameter, Partec).

3. The filtered cell suspensions of the regenerants and of controls from caryopsisderived wild-type seedlings were analysed by a Ploidy Analyser PA I (Partec) following the manufacturer's instructions.

\subsubsection{DNA Isolation, PCR and Sequencing}

1. A 200-400 mg sample of fresh leaf tissue was snap-frozen in liquid nitrogen.

2. DNA was isolated using the method of Pallotta et al. (2000) (see Note 6).

3. The target $g f p$ gene was amplified by PCR reaction using 50-100 ng genomic DNA as template. PCRs were performed in reaction volume of $40 \mu \mathrm{l}$.

4. The $g f p$ amplicons were subjected to purification and sequencing. Purification was performed using a QIAquick PCR purification kit (QIAGEN, Hilden, Germany) according to the manufacturer's instructions.

5. The PCR products of the transgenic individuals showing chromatograms with multiple peaks in the TALEN target site, which indicated the presence of multiple $g f p$ alleles among the amplicons, were cloned into pGEM-T vector. After blue-white selection, plasmid DNA was isolated from individual positive clones and sequenced.

6. Sequencing chromatograms were analysed and aligned to the wild-type sequence to see if there were differences (indels/mutations) in the targeted region.

\subsubsection{Mutant Comparison}

The target $g f p$ gene of haploids and doubled haploids, derived from hybrid plants' pollen cultures, was amplified and sequenced. $g f p$ was amplified and individual clones sequenced also from the pollen donor hybrid plants (see Note 7). The number and types of the mutations carried by doubled haploid mutants were recorded and compared with the mutations present within the parental (pollen donor) chimaeric hybrid plants. For example, 58 clones were sequenced for the pollen donor plant \#39/4, and all the 58 sequences proved to be mutated (Fig. 8.1). From this donor, 10 doubled haploids were then produced. Whereas in three of those, it was not possible to amplify gfp (see Note 8), amplification and sequencing were successful in the remaining seven DH plants, five of which carried mutant sequences, and all of these five mutations proved to be unique (Fig. 8.2) (see Note 9). As expected, doubled haploid mutants possessed their mutated allele in homozygous state. 
GFP-WI

39/4_cl-1

$39 / 4 \mathrm{cl}-2$

39/4_cl-3

$39 / 4 \mathrm{cl}-4$

$39 / 4$ cl-5

39/4 cl-6

39/4_cl-7

39/4_cl-8

$39 / 4$ cl-9

$39 / 4 \mathrm{cl}-10$

39/4 cl-11

$39 / 4$ cl-12

39/4_cl-13

$39 / 4$ cl-14

39/4 cl-15

39/4_cl-16

39/4 cl-17

39/4_cl-18

39/4_cl-19

$39 / 4 \mathrm{cl}-20$

39/4_cl-21

39/4_c1-22

39/4_cl-23

39/4_cl-24

39/4 cl-25

39/4_cl-26

39/4 c1-27

39/4_cl-28

39/4 c1-29

39/4 cl-30

39/4 cl-31

39/4 cl-32

39/4_cl-33

39/4 cl-34

39/4_cl-35

39/4 cl-36

39/4_c1-37

39/4_c1-38

39/4 cl-39

39/4_cl-40

39/4 c1-41

39/4_cl-42

39/4_cl-43

39/4 c1-44

39/4_cl-45

$39 / 4$ cl-46

39/4 cl-47

39/4_cl-48

39/4 cl-49

39/4_cl-50

$39 / 4 \mathrm{cl}-51$

39/4_cl-52

39/4_cl-53

39/4 cl-54

39/4_cl-55

$39 / 4$ cl-56

39/4 cl-57

39/4_cl-58
CACCCTGGTGAACCGCATCGAGCTGAAGGGCATCGACTTCAAGGAGGACGGCAACATCCTGGGGCACAAGCTGGAGT CACCCTGGT GAACCGCATCGAGCTGAAGG----CGACTT CAAGGAGGACGGCAACATCCTGGGGCACAAGCTGGAGI CACCCTGGT GAACCGCATCGAGCTGAAGG----CGACTT CAAGGAGGACGGCAACATCCTGGGGCACAAGCTGGAGI CACCCTGGT GAACCGCATCGAGCTGA---------CIT CAAGGAGGACGGCAACATCCTGGGGCACAAGCTGGAGT CACCCTGGT GAACCG CATCGAGCTGA----------CIT CAAGGAGGACGGCAACATCCTGGGGCACAAGCTGGAGI CACCCIGGT GAACCGCATCGAGCTGA---.-----CIT CAAGGAGGACGGCAACATCCTGGGGCACAAGCTGGAGI CACCCIGGI GAACCGCATCGAGCTGAAG-------CITCAAGGAGGACGGCAACATCCTGGGGCACAGGCTGGAGI CACCCIGGT GAACCG CAICGAGCTGAAGG---ICGACTI CAAGGAGGACGG CAACATCCTGGGGCACAAGCTGGAGT CACCCTGGT GAACCGCATCGAGCTGAAGG---ICGACTI CAAGGAGGACGG CAACATCCIGGGGCACAAGCTGGAGT CACCCTGGT GAACCG CATCGAGCTGAAGG---I CGACTI CAAGGAGGACGGCAACATCCTGGGGCACAAGCTGGAGT

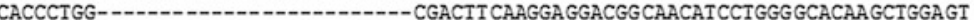
CACCCTGGI GAACCG CATCGAGCTGAAGG---CACAAGCTGGAGT CACCCTGGI GAACCG CATCGAGCTGAAG-CACCCIGGT GAACCG CATCGAGCTGAAG---1 CACCCTGGT GAACCGCATCGAGCTGAAG-CACCCIGGT GAACCG CATCGAGCTGAAG-CACCCTGGI GAACCG CATCGAGCTGAAG-_- TACAACTACAAGGAGI CACCCIGGI GAACCGCATCGAGCTGAAG--.--

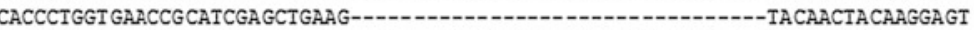
CACCCIGGT GAACCG CATCGA-------CIT CAAGGA GGACGGCAACATCCTGGGGCACAAGCTGGA GI

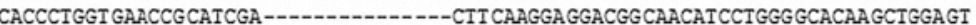
CACCCIGGT GAACCG CATCGAGCTGAAGG------AGGACGG CAACATCCAGGGGCACAAGCTGGAGT CACCCTGGT GAACCGCATCGAGCTGAAGG----------AGGACGGCAACATCCTGGGGCACAAGCTGGAGT CACCCTGGT GAACCG CATCGAGCTGAAGG--.--AGGACGG CAACATCCTGGGGCACAAGCTGGAGT CACCCIGGT GAACCG CATCGAGCTGAAGG------------AGGACGGCAACATCCTGGGGCACAAGCTGGAGI CACCCTGGT GAACCG CATCGAGCTGAAGG-------------AGGACGG CAACATCCTGGGGCACAAGCTGGAGI CACCCIGGT GAACCGCATCGAGCTGAAGG---------AGGACGGCAACATCCTGGGGCACAAGCTGGAGT CACCCTGGT GAACCG CATCGAGCTGAAGG-----------AGGACGG CAACATCCTGGGGCACAAGCTGGAGT CACCCIGGT GAACCGCATCGAGCIGAAGG---------AGGACGGCAACATCCTGGGGCACAAGCTGGAGI CACCCIGGI GAACCG CATCGAGCTGAAGG---------AGGACGGCAACATCCTGGGGCACAAGCTGGAGT CACCCIGGT GAACCGCATCGAGCTGAAGG----CGACTI CAAGGAGGACGGCAACATCCTGGGGCACAAGCTGGAGI CACCCTGGT GAACCG CATCGAGCTGAAGG-----CGACTI CAAGGAGGACGGCAACAICCTGGGGCACAAGCTGGAGI CACCCTGGT GAACCG CATCGAGCTGAAGG-----CGACTI CAAGGAGGACGGCAACATCCIGGG GCACAAGCTGGAGT

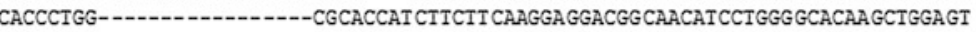
CACCCTGG--1----CGCACCAT CTICTT CAAGGAGGACGG CAACATCCTGGGGCACAAGCTGGAGT CACCCTGG-------CGCACCATCTICTT CAAGGAGGACGGCAACATCCTGGGGCACAAGCTGGAGT CACCCIGGT GAACCGCATCGA--------CGTTGTGACTI CAAGGAGGACGGCAACATCCTGGGGCACAAGCTGGAGI

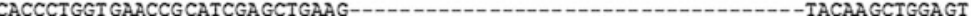
CACCCTGGT GAACCG CATCGAGCTGAAGGG-----ACTICAAGGAGGACGGCAACAICCTGGGGCACAAGCTGGAGT CACCCTGGT GAACCGCATCGAGCTGAAGGG-----ACTTCAAGGAGGACGGCAACATCCTGGGGCACAAGCTGGAGT

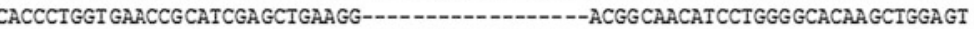
CACCCIGGT GAACCG CATCG-------GCGACTI CAAGGAGGACGGCAACATCCTGGGGCACAAGCTGGAGI CACCCIGGT GAACCGCATCG---AGCT GAAGGGCGACTI CAAGGAGGACGGCAACATCCTGGGGCACAAGCTGGAGI CACCCTGGI GAACCGCATCGAGCTGAAGGGC---GACTTCAAGGAGGACGGCAACATCCTGGGGCACAAGCTGGAGT CACCCTGGT GAACCGCATCGAGCTGAAGGGC---GACTTCAAGGAGGACGGCAACATCCTGGGGCACAAGCTGGAGT

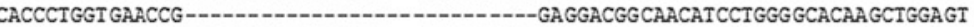
CACCCTGGT GAACCGCATCGAGCTGAAGGGC---AACTI CAAGGAGGACGGCAACATCCTGGGGCACAAGCTGGAGT CACCCTGG--C-1

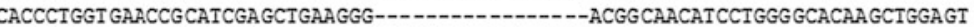
CACCCTGGT GAACCGCATCGAGCTG-------CGACTT CAAGGAGGACGGCAACATCCTGGGGCACAAGCTGGAGT CACCCIGGT GAACCGCATCGAGCTGAAGGG---1---AGGACGGCAACATCCTGGGGCACAAGCTGGAGI CACCCIGGT GAACCG CATCGAGCIGAAGGG-------AGGACGG CAACATCCIGGGGCACAAGCIGGAGT CACCCTGGT GAACCGCATCGAGCTGAAGGG----1.--AACATCCTGGGGCACAAGCTGGAGT CACCCTGGT GAACCG CATCGAGCTGAAGGG--TCGACTI CAAGGAGGACGG CAACATCCTGGGGCACAAGCTGGAGT CCGCCTGCAGGICGACCATAT GGGAGAGCTCCCAACGCGITGGAI GCATAGCTIGAGTATICTATAGIGTCACCTAA CCGCCIGCAGGICGACCATAT GGGAGAGCTCCCAACGCGITGGAT GCATAGCTTGAGTATTCTATAGTGTCACCT AA CACCCTGGT GAAGIT CGAGGGCGACACCCTGGT GAACCGCATCGACITCAAGGAGGACGGCAACATCCT GGGGCACA CACCCTGGT GAACCGCATCAAGICCGCCAIGCCCGAAGG CTACGI CCAGGAGCGCACCATCIT CITCAAGGACGACG

Fig. 8.1 Alignment of the various cloned $g f p$ mutant sequences of the hybrid plant \#39/4. The underlined sequences represent TALEN-binding sites in wild-type $g f p$. Deletions are indicated with dashes. Note that long insertions in addition to deletions are present in the last four sequences 


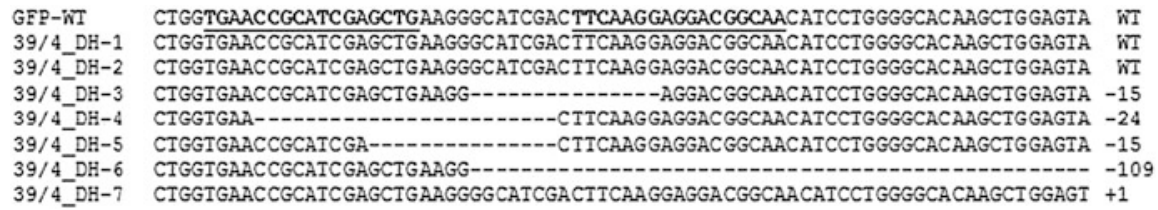

Fig. 8.2 $g f p$ alleles found in the pollen-derived homozygous doubled haploids produced from the hybrid plant \#39/4 are aligned with the wild type $g f p$ sequence

\subsection{Notes}

1. Five distinct mutations were inherited among 10 doubled haploid siblings in the example presented in this chapter.

2. Cultivar 'Igri' lines expressing either the left or right TALEN units were produced by transformation of immature pollen cultures using the method described in Chap. 7. For more details about the TALEN vectors, see Gurushidze et al. (2014).

3. All materials coming into contact with the explant need to be sterile and pre-cooled to $4{ }^{\circ} \mathrm{C}$, and all solutions should be kept on ice during the pollen isolation and purification procedure. Liquid transfer is most effectively carried out using a battery-operated pipette with filter-stopped 5 or $10 \mathrm{ml}$ tips.

4. At this step, it is critical that the two layers do not become mixed. For that reason, the centrifugation step is performed with the acceleration and deceleration forces of the centrifuge being reduced to $30 \%$.

5. The exchange of SMB to KBP medium is to be done with particular care to avoid taking up embryogenic pollen. To this end, the pipette should be slightly pressed with its tip to the bottom of the dish, so as to control the uptake of medium, while the cultivated pollen is collecting around the tip without being taken up.

6. For molecular analyses (DNA isolation, PCR) of the transgenics, it is recommended to use filter tips because false positives are often detected due to cross-contamination of samples, particularly because of the frequent use of standard marker and/or selection genes.

7. Ten to 65 clones were analysed per hybrid plant. Mutant alleles represented 62.5 to $100 \%$ of the individually cloned sequences.

8. Large deletions including at least one primer-binding site might be the most plausible reason for failed amplification.

9. Among the five different mutations found in pollen-derived 10 doubled haploid siblings, 2 were already detected among the 58 mutations of their hybrid mother plant (39/4), while 3 mutations were 'new', i.e. not present among the 58 previously sequenced clones.

Open Access This chapter is distributed under the terms of the Creative Commons AttributionNoncommercial 2.5 License (http://creativecommons.org/licenses/by-nc/2.5/) which permits any noncommercial use, distribution, and reproduction in any medium, provided the original author (s) and source are credited. 
The images or other third party material in this chapter are included in the work's Creative Commons license, unless indicated otherwise in the credit line; if such material is not included in the work's Creative Commons license and the respective action is not permitted by statutory regulation, users will need to obtain permission from the license holder to duplicate, adapt or reproduce the material.

\section{References}

Bitinaite J, Wah DA, Aggarwal AK, et al. (1998) FokI dimerization is required for DNA cleavage. Proc Natl Acad Sci USA 95:10570-10575

Christian M, Cermak T, Doyle EL, et al. (2010) Targeting DNA double-strand breaks with TAL effector nucleases. Genetics 186:757-761

Gurushidze M, Hensel G, Hiekel S, et al. (2014) True-breeding targeted gene knock-out in barley using designer TALE-nuclease in haploid cells. PloS One 9:e92046

Kumlehn J, Serazetdinova L, Hensel G, et al. (2006) Genetic transformation of barley (Hordeum vulgare L.) via infection of androgenetic pollen cultures with Agrobacterium tumefaciens. Plant Biotechnol J 4:251-261

Moscou MJ, Bogdanove AJ (2009) A simple cipher governs DNA recognition by TAL effectors. Science 326:1501

Pallotta MA, Graham RD, Langridge P, et al. (2000) RFLP mapping of manganese efficiency in barley. Theor Appl Genet 101:1100-1108

Wendt T, Holm PB, Starker CG, et al. (2013) TAL effector nucleases induce mutations at a pre-selected location in the genome of primary barley transformants. Plant Mol Biol 83:279-285

Wendt T, Holm PB, Starker CG, Christian M, Voytas DF, Brinch-Pedersen H, Holme IB (2014) TALEN-mediated mutagenesis in primary barley transformants. Proceedings on plant transformation technologies III, Vienna, 12-15 Feb 2014, p 29 